\title{
A GOVERNANÇA DOS USUÁRIOS DE DROGAS NA VIDA NOTURNA: UM ESTUDO DE CASO EM LONDRINA-PR
}

\author{
Luiz Fernando Ferreira Paz ${ }^{1}$
}

\begin{abstract}
Resumo
As pesquisas sobre a governança dos mercados de drogas estão concentradas, basicamente, em analisar o papel de atores estatais nesse processo. Os modos como atores não estatais, como proprietários, porteiros e seguranças de espaços de entretenimento adulto, participam da governança desses mercados têm sido praticamente ignorados pela literatura. O objetivo deste trabalho é investigar a maneira como uma casa noturna do centro de Londrina/PR governa o consumo de drogas lícitas e ilícitas em seu interior. A partir da perspectiva teórica da governança nodal, o trabalho busca saber quais mentalidades, tecnologias e práticas estão presentes no interior da casa noturna e como ela orienta o modo como o espaço vê e trata os usuários de drogas lícitas e ilícitas. A pesquisa coletou dados por meio da pesquisa etnográfica e da entrevista de profissionais da vida noturna. Os resultados mostram que existe pouco atrito entre a equipe de segurança e os usuários de drogas, que se relacionam orientados por uma lógica mais instrumental e menos moral. As consequências desses achados são discutidas.
\end{abstract}

Palavras-Chave: Vida Noturna; Governança da Segurança; Drogas lícitas e ilícitas.

\section{INTRODUÇÃO}

O policiamento estatal dos mercados de drogas lícitas e ilícitas tem recebido bastante atenção da bibliografia acadêmica das ciências sociais e da criminologia. A agenda de pesquisa sobre os modos como organizações, fornecedores e consumidores de drogas são governados tem se ocupado de muitos temas. Parte das pesquisas vem buscando entender as políticas estatais proibicionistas que, sob a liderança de países como EUA, ganharam espaço na maior parte das democracias ocidentais durante o século XX (SCHECAIRA, 2014; MORAIS, 2006). Outra parte tem se concentrado em analisar o fracasso da política de guerra às drogas e as suas consequências sociais que ela tem gerado, especialmente para as populações marginalizadas, vítimas preferenciais da ação seletiva do sistema de justiça criminal (LEMGRUBER; BOITEUX, 2014).

Apesar da importância dessa reflexão, ela apresenta lacunas, na medida em que se concentra basicamente em entender o papel dos atores estatais na governança dos mercados de drogas. Os

\footnotetext{
${ }^{1}$ Universidade Estadual de Londrina (UEL), Centro de Letras e Ciências Humanas (CLCH), Integrante do Laboratório de Estudos sobre Governança da Segurança (LEGS) - www.legsuel.org, luizfer007paz@ gmail.com.
} 
modos como atores não estatais, como proprietários, porteiros e seguranças de espaços de entretenimento adulto, participam da governança desses mercados de drogas têm sido praticamente ignorados pela literatura, especialmente a nacional. Dentro dessa produção, são importantes exceções o trabalho de Hobbs et al. (2003) sobre as estratégias informais adotadas pelos seguranças para governar a vida noturna na Inglaterra; o estudo de Sanders (2005) sobre a "cultura do uso de drogas" e a normalização do consumo de ecstasy em uma casa noturna de Londres; e o recente trabalho de Søgaard et al. (2017) sobre as parcerias entre atores públicos e privados no policiamento de usuários de drogas em um distrito de vida noturna da Dinamarca.

Este trabalho visa contribuir para essa incipiente literatura que analisa a atuação de atores não estatais na governança dos mercados de drogas. Ele investiga o modo como uma casa noturna do centro de Londrina (PR) vê e trata o consumo de drogas em seu interior. Para entender essa questão, o trabalho mobiliza a teoria da governança nodal proposta por Shearing e desenvolvida em conjunto com colaboradores (JOHNSTON; SHEARING, 2003; WOOD; DUPONT, 2006). A partir dessa teoria, espaços como bares e casas noturnas podem ser interpretados como nós de governança dotados de mentalidades (modos de pensar sobre a segurança e como abordá-la), tecnologias (técnicas e métodos utilizados para converter mentalidades em ações) e práticas (formas de agir) que visam influir no curso dos eventos para ordená-los de determinada maneira. Levando isso em consideração, o trabalho busca responder às seguintes questões: quais mentalidades, tecnologias e práticas são mobilizadas pelo espaço de entretenimento noturno para governar o consumo de drogas lícitas e ilícitas em seu interior? Como os usuários de drogas são cotidianamente tratados nesse espaço?

Para responder às questões acima, o artigo está organizado em quatro partes. A primeira discute a abordagem teórica utilizada para iluminar o objeto estudado, isto é, a teoria da governança nodal. Já a segunda apresenta e discute a metodologia e os procedimentos de pesquisa utilizados na coleta e na análise dos dados. A terceira parte apresenta e discute os dados coletados. Por fim, o trabalho conclui sumarizando os resultados.

\section{GOVERNANÇA NODAL}

A proliferação da ideologia neoliberal nas democracias ocidentais veio acompanhada do deslocamento da autoridade do Estado, enquanto o regulador da ordem, para atores não estatais, 
sejam figuras suplementares ao policiamento estatal, sejam agentes efetivos nas atividades de policiamento em determinados espaços (SHEARING, 1992). Nesse sentido, houve o que a literatura tem chamado de "pluralização do policiamento", uma nova realidade em que o Estado deixa de ser o único ator que define a ordem e governa a segurança na sociedade. Essas mudanças levaram ao surgimento de uma série de abordagens teóricas críticas às visões estadocêntricas, dominantes no campo dos estudos sobre policiamento, muitas delas inspiradas na tradição foucaultiana, que pensa o poder político como algo descentrado e disperso. Uma das abordagens mais proeminentes é a da governança nodal.

A noção de governança da segurança diz respeito às tentativas de moldar e influenciar eventos, sejam eles resultante de condutas individuais, e/ou de grandes populações, objetivando construir a ordem de um dado espaço (WOOD; DUPONT, 2006). Nesse sentido, a segurança pode ser governada tanto por atores estatais (públicos) quanto por atores não estatais (privados). Segundo Shearing (2006, p 11, tradução nossa), "governos privados que se dedicam a orientar o fluxo de eventos para promover a segurança são, como os Estados, auspícios que promovem estratégias intencionais que visam oferecer garantias de proteção"2. Governos desse tipo se desenvolvem, por exemplo, no que os estudiosos chamam de "propriedades privadas de massa". Essas propriedades incluem shoppings centers, condomínios, universidades e outros espaços privados de uso coletivo, onde as práticas de controle social não são exercidas pela polícia, mas por seguranças que agem de acordo com os interesses dos atores que controlam tais espaços (KEMPA; STENNING; WOOD, 2004). Por esse motivo, teóricos como Shearing (2006, p. 11, tradução nossa) concebem os atores que controlam esses espaços como governos privados, isto é, “entidades não estatais que operam não apenas como provedoras de governança em nome de agências estatais, mas como auspícios de governança em si mesmas"3.

Os governos privados são fenômenos que ocorrem globalmente, mas os estudiosos, em geral, não os têm reconhecido como auspícios de governança (SHEARING, 2006). Para exemplificar a relevância do tema, estudos realizados na região metropolitana de São Paulo mostram que a segurança privada está mais presente no cotidiano do paulistano do que o policiamento estatal, visto que a atuação dos profissionais da segurança privada se dá, geralmente, em espaços privados de massa, como terminais de transporte público, condomínios residenciais e empresariais, parques

\footnotetext{
2 "Private governments that engage in steering the flow of events to promote security are, like states, auspices that engage in purposive strategies involving the initiation of techniques which are intended to offer guarantees of security".

3 "Non-state entities that operate not simply as providers of governance on behalf of state agencies but as auspices of governance in their own right".
} 
industriais, shoppings centers, estádios de futebol, parques recreativos etc., isto é, locais em que os indivíduos encontram-se inseridos na maior parte do tempo (LOPES, 2013).

Uma casa noturna, nessa perspectiva, pode ser considerada uma entidade de governança da segurança em si mesma. Bachett e Lopes (2020), em estudo sobre o poder de revista de seguranças privados em espaços de consumo, definiram as casas noturnas como uma das propriedades privadas de massa que comumente empregam serviços de segurança privada, seja orgânica (contratação de seguranças diretamente pelas casa), seja terceirizada (contratação de empresas que fornecem seguranças para as casas). Essas propriedades privadas de massa fomentam a indústria da segurança privada e, por consequência, constituem nódulos dentro de uma rede maior de auspícios de governança da segurança. Um nó é caracterizado por sua pluralidade no modo como interage com outros nós e a intensidade dessa interação é muito relativa de nó para nó - essa interação pode se dar por meio da influência, da acessibilidade e/ou da eficácia que um nó tem sobre outros, por exemplo. Nesse sentido, cada nó tem uma estrutura particular e ele não precisa ser desenvolvido, intencionalmente, como uma ferramenta de governança ou de regulação. Para ser efetivamente um nó de governança, ele deve ter alguma forma institucional, ainda que temporária. Não precisa ser legalmente reconhecido como uma entidade, mas ele precisa ter estabilidade suficiente e estrutura organizacional para possibilitar a mobilização de recursos, de mentalidades e de tecnologias ao longo do tempo. Os critérios utilizados pelo nó para mobilizar recursos e tecnologias podem ser fundamentados em leis, em ameaças, em pressão social ou em estigma (BURRIS; DRAHOS; SHEARING, 2005).

Esses nós de governança podem ser definidos como espaços que realizam a governança a partir de mentalidades, tecnologias, recursos e instituições. As mentalidades caracterizam os modos de se pensar a governança, isto é, a maneira pela qual ela será concebida. Já as tecnologias são conceituadas como os métodos, as estratégias e as táticas utilizadas pelos nós, manifestando-se na forma de patrulhamento, de vigilância, de ameaça ou uso da força, de ameaça ou aplicações de punição, dentre outros. Instituições se referem a estruturas organizacionais duradouras - formais ou informais -, nas quais os nós se apoiam para a realização dos seus objetivos. Por fim, os recursos são os meios utilizados pelos nós para sustentar as mentalidades, as tecnologias e as instituições que o compõem. Esses recursos podem ser sociais (redes de relacionamentos), econômicos (dinheiro/orçamento), políticos (capacidade de pressão sobre o Estado), técnicos (conhecimentos) ou mesmo simbólicos (prestígio) (BURRIS; DRAHOS; SHEARING, 2005; JOHNSTON, L; SHEARING, 2003). 
A dimensão mais importante de um nódulo de governança da segurança, e um dos focos centrais deste trabalho, é a mentalidade implementada no espaço. Uma mentalidade reflete um modo de pensar - a maneira pela qual o mundo é interpretado - e, como resultado, o modo que reagimos a situações e a circunstâncias que enfrentamos no cotidiano. A mentalidade traduz em ações as percepções de ordem de um espaço e a maneira como ela deve ser gerida. Nesse sentido, ela se apresenta de forma mais implícita do que explicita. Os métodos de governança, quaisquer que sejam as razões para adotá-los, refletem, implicitamente, uma mentalidade (JOHNSTON, L; SHEARING, 2003). Diferentes mentalidades têm sido associadas à governança da segurança, tais como as punitivas, as de gestão de riscos e as de redução de danos. A governança da segurança baseada em uma mentalidade punitiva tende a focar crimes ou desvios já ocorridos e que devem ser vingados. Para isso, normalmente, ela se vale de tecnologias de coerção física para prender aqueles que tenham perturbado determinada ordem, na expectativa de que isso tenha um efeito de intimidação (ou dissuasão) sobre o comportamento futuro daquela pessoa e de outros que eventualmente considerem cometer desvios. Por outro lado, a mentalidade de gerenciamento de risco enfatiza modos de governança a distância que se preocupam mais com evitar eventos futuros do que com reprimir eventos passados. Em outros termos, essa mentalidade está preocupada em avaliar e minimizar riscos por meio de tecnologias variadas, que focam não apenas os ofensores, mas, também, potenciais vítimas que possam ter comportamentos que criam oportunidades para eventos indesejados (JOHNSTON, L; SHEARING, 2003). Já as mentalidades de redução de danos são aquelas que buscam minimizar as consequências de determinado comportamento desviante sem desrespeitar a autonomia e as liberdades daqueles que assumem tais comportamentos. Essas mentalidades são comuns em políticas de saúde pública que visam distribuir recursos, como seringas, agulhas e cachimbos, a usuários de drogas, enquanto uma forma de minimizar as consequências do uso compartilhado desses apetrechos para a saúde dos indivíduos.

Outra dimensão relevante de um nódulo de governança, central neste trabalho, são as tecnologias, que podem ser descritas como ferramentas que viabilizam a implementação da mentalidade e os processos de governança. Os agentes que executam a governança da segurança precisam de ferramentas para construir a ordem. Além de ferramentas físicas, como armas, bastões, veículos, avisos de vigilância etc., também são requeridos, para a governança da segurança, ferramentas legais, como o poder de prender, revistar, apreender ou banir; ferramentas simbólicas, como o respeito do público e a própria credibilidade que a instituição ou o agente da ordem desfruta; ferramentas pessoais, como personalidade, arsenal físico, carisma, habilidades de comunicação e 
resolução de conflitos. Essa caixa de ferramentas tende a variar enormemente entre os profissionais que executam a ordem em diferentes espaços, que diferem de acordo com fatores como idade, experiência no trabalho, gênero etc. (JOHNSTON, L; SHEARING, 2003; LOPES, 2015). Os diferentes modos e processos de governança requerem ferramentas diferentes e combinações de ferramentas para atingir a efetividade de seus objetivos prescritos na mentalidade.

Essa pesquisa parte da ideia de que as casas noturnas são propriedades privadas de massa que podem ser tomadas como nós de governança da segurança. Enquanto nós de governança, esses espaços contam com mentalidades, tecnologias, recursos e institucionalidades próprios, mobilizados com o objetivo de dirigir pessoas e coisas segundo os interesses de seus controladores. Neste trabalho, em particular, interessa compreender quais mentalidades e quais tecnologias conformam as práticas que governam o consumo de drogas lícitas e ilícitas dentro de uma casa noturna de Londrina/PR. O consumo de drogas em espaços de entretenimento adulto, como casas noturnas, tem sido destacado por alguns estudos (HOBBS et al. 2003; SANDERS, 2005; SØGAARD et al. 2017.). Entretanto, pouco se sabe a respeito do modo como esse consumo é governado no interior desses espaços, já que os estudos voltados para a questão das drogas no país têm focado, basicamente, na governança dos usuários em espaços públicos (LEMGRUBER; BOITEUX, 2014; SCHECAIRA, 2014; MORAIS, 2006). Assim, com essa pesquisa, espera-se contribuir para uma melhor compreensão do problema da governança dos mercados de drogas em nossa sociedade.

\subsection{METODOLOGIA}

A pesquisa foi realizada em um espaço de entretenimento noturno, localizado no centro de Londrina/PR, voltado para o público LGBTQI+. A escolha do caso foi realizada a partir de um estudo piloto que, junto a frequentadores e a trabalhadores locais, levantou informações acerca da vida noturna na cidade. Nesse piloto, foram realizadas conversas informais com cinco pessoas, bem como visitas em dois espaços. A casa noturna selecionada funciona às sextas e aos sábados com open-bar e com preços relativamente baixos. Essas características fazem com que o espaço receba um público grande e que faz uso excessivo de álcool. A combinação desses dois elementos torna essa casa noturna um espaço qualitativamente interessante de ser analisado, já que o grande fluxo de pessoas alcoolizadas desafia a governança da ordem no espaço.

Para pesquisar a casa noturna selecionada, recorreu-se ao método etnográfico e a entrevistas semiestruturadas. Foram realizadas quatro visitas encobertas no espaço, para o levantamento de 
dados etnográficos, nas quais as pessoas observadas não sabiam da minha condição de pesquisador (ver Quadro 1). De acordo com a literatura, "a abordagem etnográfica se constrói tomando como base a ideia de que os comportamentos humanos só podem ser devidamente compreendidos e explicados se tomarmos como referência o contexto social onde eles atuam" (HASSEN et al. 2000, p. 53) ${ }^{4}$. Ela é, particularmente, relevante para propostas de pesquisa como a deste trabalho, que exige a observação do comportamento de seguranças e de outros funcionários diante de pessoas portando ou usando drogas. Não por acaso esse é o método que foi empregado em um dos mais destacados estudos já realizados sobre a governança da segurança na vida noturna, que resultou no livro Bouncers: violence and governance in the night-time economy, de Dick Hobbs et al. (2003). Nessa pesquisa, os autores empregam o método etnográfico para descrever e para analisar as estratégias informais adotadas por agentes de segurança na construção da ordem da vida noturna na Inglaterra. Segundo a declaração de um segurança entrevistado, "você tem que ter uma mentalidade de portaria, uma mentalidade de rua, você tem que saber como ler pessoas, linguagem corporal, expressões faciais. Você aprende muito apenas olhando pessoas" (HOBBS et al. 2003, p. 120, tradução nossa $)^{5}$. Essa citação revela que os seguranças têm seus próprios códigos de conduta, os quais os ajudam a identificar eventuais clientes problemáticos. Portanto, compreender o que é entendido por eles como "mentalidade de portaria, mentalidade de rua" não seria possível sem o método etnográfico. Assim como nas casas noturnas da Inglaterra, a casa noturna pesquisada em Londrina apresenta semelhanças e particularidades que serão discutidas nos resultados da pesquisa.

Quadro 1: Informações sobre as visitas de campo

\begin{tabular}{|l|l|l|}
\hline \multicolumn{3}{|c|}{ Caderno de Campo } \\
\hline Visitas & Data & Horário \\
\hline Primeira Visita & $19 / 10 / 2019$ & A partir das 12:30 às 04:00 \\
\hline Segunda Visita & $16 / 11 / 2019$ & A partir das 12:00 às 04:20 \\
\hline Terceira Visita & $08 / 02 / 2020$ & A partir das 23:00 às 03:30 \\
\hline Quarta Visita & $22 / 02 / 2020$ & A partir das 01:00 às 04:00 \\
\hline
\end{tabular}

Além da pesquisa etnográfica, que realizou observação participante encoberta, foram realizadas entrevistas em que os entrevistados sabiam da condição de pesquisador do entrevistador. Nessas entrevistas, foi comunicado que todas as informações obtidas por meio delas seriam usadas

\footnotetext{
${ }^{4}$ A etnografia, durante muito tempo, foi considerada um método carregado de irrelevâncias empíricas, porque registrava detalhes pífios de uma sociedade. Porém, a realidade tem mostrado que os bons trabalhos etnográficos resultam em uma riqueza de dados empíricos que possibilitam a análise, a reavaliação e a eventual contestação de determinada realidade que se desenrola em um dado contexto social (WOORTMANN, 2018).

5 "You have to have a door mentality, a street mentality, you have to know how to read people, body language, facial expressions. You learn so much just looking at people".
} 
somente para fins acadêmicos e sem que os nomes reais dos entrevistados fossem revelados. Com o consentimento dos pesquisados, foram entrevistados uma ex-segurança da casa noturna; um usuário de drogas ilícitas frequentador do espaço; e uma promoter (ver Quadro 2). Excetuando a entrevista com a ex-segurança, todas as demais foram realizadas por meio de vídeo chamada, em razão das medidas de distanciamento social decorrentes da situação de pandemia, declarada quando a pesquisa empírica ocorria.

Quadro 2: Informações sobre as entrevistas realizadas

\begin{tabular}{|l|l|l|}
\hline \multicolumn{3}{|c|}{ Entrevistas } \\
\hline Entrevistado & Duração & Data \\
\hline Ex-segurança & 01 hora 16 minutos & $05 / 03 / 2020$ \\
\hline Usuário & 11 minutos & $26 / 03 / 2020$ \\
\hline Promoter & 26 minutos & $19 / 04 / 2020$ \\
\hline
\end{tabular}

As entrevistas foram transcritas e as observações realizadas foram anotadas em um caderno de campo. O corpus de pesquisa qualitativo resultante desses procedimentos foi, então, analisado "palavra por palavra", a partir das técnicas de microanálise sugeridas por Strauss e Corbin (2008).

Antes da apresentação dos resultados da pesquisa, é importante mencionar que a fase de levantamento de dados estava em curso quando a crise sanitária provocada pelo Coronavírus eclodiu e quando as políticas de distanciamento social tiverem início. A crise interditou a possibilidade de novas incursões planejadas ao campo e dificultou sobremaneira a realização de mais entrevistas, que dependem do estabelecimento de relações de confiança entre pesquisador e pesquisado, em contatos face a face, que se tornaram impossíveis. Assim, embora o material empírico produzido no estudo seja rico e suficiente para a realização de importantes inferências qualitativas acerca do fenômeno analisado, ele é aquém do que teria sido gerado em um cenário de normalidade.

\subsubsection{Resultados e Discussão}

As propriedades privadas de massa, por meio da segurança privada, estipulam regras de acesso e de convivência dentro dos seus espaços que podem divergir ou reiterar as normas que orientam a ordem nos espaços públicos policiados pela polícia. Nesse sentido, os dados obtidos por meio de entrevistas mostram que a equipe de segurança tem uma relação com os usuários de drogas 
de pouco atrito. Questionada sobre a abordagem utilizada com os clientes pegos usando drogas ilícitas dentro do estabelecimento, uma ex-segurança da casa relata que:

Eu só pedia para me acompanhar até o caixa e pedia a comanda. A pessoa sabe que o que está fazendo é errado. Não preciso constranger dizendo que ela está usando drogas. [...] Se eu chegar na pessoa dizendo 'a, você perdeu porque está no banheiro usando droga e tudo mais'. Perai, o que eu estou fazendo? Abuso de autoridade. Estou constrangendo a pessoa, uma humilhação desnecessária. Todo mundo que esta a sua volta vai ficar sabendo que você estava usando droga se isso acontecer [...]. E assim, nós seguranças ali temos que ser como padres. Então pelo menos eu, falo de mim, o que acontece ali, fica ali. Se eu comento, é igual aqui agora, não cito nomes (ENTREVISTA, dia 05/03/2020).

Por meio dessa fala, é possível identificar que, no trato com os usuários de drogas, o diálogo é fundamental para a equipe de segurança, e qualquer coisa para além disso pode ser interpretada como "abuso de autoridade". A expressão "eu só pedia", por exemplo, reflete o modo como a casa noturna trata o usuário, isto é, sem expô-lo, evitando uma "humilhação desnecessária", conforme a entrevistada relata. Esse modus operandi corrobora a literatura do policiamento privado. Tendo em vista que os seguranças não têm poder para dobrar vontades através do uso da força física e ferramentas coecitivas como a polícia tem, a casa noturna adota um policiamento mais consensual, de modo que não venha a contranger os usuários de drogas. Além disso, é preciso considerar que seguranças privados são relativamente vulneráveis a processos por abuso de poder, como lembram Stenning (2000), a partir de exemplos da realidade americana, e Lopes (2018), a partir do estudo de decisões judiciais de segundo instância proferidas nos estados de São Paulo e do Paraná. Assim, conforme a ex-segurança relata, no contexto de uma casa noturna, expor um cliente usuário de drogas pode ser interpretado como "abuso de autoridade". Ou seja, os métodos de policiamento dentro desse local são baseados no diálogo, instrumentalizando o consenso como base da relação entre o segurança e o cliente. Essa relação é explicitada na fala da ex-segurança, quando ela diz que "só pedia", por exemplo.

Evitar expor clientes parece revelar uma lógica de atuação diferente da que está presente nos espaços públicos policiados por organizações estatais. Um cliente pego usando drogas representa uma rede de potenciais clientes que, eventualmente, pode frequentar a casa. Uma abordagem pouco atritiva é fundamental para a manutenção dessa clientela. Esculachar um cliente usuário de drogas afetaria toda rede de usuários. Assim, para a equipe de segurança, é necessário "ser como padres", pois "o que acontece ali, fica ali”, garantindo, assim, que pessoas não serão expostas e a clientela perdida. Esse comportamento também foi identificado na equipe de segurança de uma casa noturna inglesa, onde os seguranças tinham o dever de controlar quem era aceitável e quem não era dentro 
do local, ao mesmo tempo em que tinham que manter o "caixa rodando" (HOBBS et al. 2003).

Esse tipo de abordagem pouco atritiva é confirmado por um usuário da casa noturna já abordado pela equipe de segurança. Segundo o entrevistado, "Ela [segurança] foi bem tranquila, só chegou e eu falei 'Ah, mas...' e ela 'Não, não, só vem, só vem'. Daí eu perguntei 'eu não vou poder entrar mais?' e ela 'Não, vai poder entrar sim. Ninguém bloqueou sua conta não'” (ENTREVISTA, dia 26/03/2020). A pesquisa participante também apontou para a mesma direção, como mostra o trecho abaixo, retirado do caderno de campo:

Segundo os depoimentos de alguns seguranças, [...] com os usuários pegos usando ou portando drogas como cocaína e maconha, têm-se uma certa tolerância no sentido de permitir o cliente permanecer no local com a condição de que entregue a droga à equipe de segurança ou use fora da casa, permitindo-o voltar sem ela (CAMPO, 08/02/2020).

Assim, apesar de drogas como cocaína e maconha serem proibidas, se descobertas pelos seguranças, não há nenhum processo punitivo previsto nas leis que orientam o comportametno dos agentes públicos vinculados ao sistema de justiça criminal, especialmente os policiais. Isso porque vigora, no interior da casa noturna, uma noção de ordem que deve ser garantida pelos seguranças, diferente da noção de ordem pública, que deve ser garantida pelos agentes estatais. De acordo com as regras que regem o funcionametno do sistema de justiça crirminal, as abordagens com usuários de drogas ilícitas deveriam ser encaminhadas de outra maneira: o segurança deveria acionar a polícia, que, por sua vez, levaria o usuário à delegacia, onde ele prestaria depoimento; posteriormente, o infrator ficaria obrigado a comparecer ao JECrim (Juizado Especial Criminal) para a audiência, podendo ser penalizado com uma multa e advertência verbal, prestação de serviço, medida educativa de comparecimento à programa ou curso educativo (FILHO, 2007). Essa é a maneira como os usuários de drogas ílicitas devem ser governados, mas a casa noturna funciona como um nódulo de governança paralelo que possui regras próprias para lidar com os usuários de drogas. Em outros termos, opera na casa noturna um sistema de justiça privado que dá outro encaminamento a quem é pego portando ou consumindo drogas no seu espaço. Como mostra a entrevista abaixo, quando isso ocorre, são colocadas duas opções para o cliente usuário de drogas: ele, acompanhado de um segurança, guarda a droga em qualquer lugar fora da casa e depois volta, ou entrega a droga para o segurança e o acompanha até o banheiro, para jogá-la fora:

A maioria das vezes quando pegamos a droga o que acontece: nós seguranças não podemos reter [a droga], não podemos segurá-la. Nós damos duas oportunidades: ou a pessoa pega [a droga] e guarda com a condição que o segurança veja ela guardando, se ela esta guardando mesmo no carro ou em qualquer lugar; ou ela nos acompanha até o banheiro para jogarmos 
a droga dentro da privada. E isso é no ato. Sempre é jogada a droga na frente do cliente para evitar que o segurança seja acusado de confiscar a droga para ele. E isso acontece em qualquer local. O segurança não pode pegar a droga e confiscá-la sem te dar alternativas (ENTREVISTA, dia 05/03/2020).

O comportamento dos seguranças revelado na fala acima também pode ser interpretado pela lógica econômica descrita anteriormente, pois barrar clientes portando drogas compromete a lucratividade do estabelecimento. Nesse sentido, esse dado vai ao encontro do que a literatura sobre segurança privada identifica, pois a natureza do policiamento privado, geralmente, preocupa-se com questões mais instrumentais do que morais, isto é, proteger os interesses do estabelecimento é mais importante que combater o crime (SHEARING; STENNING, 1983). Em outras palavras, a governança da segurança é realizada de maneira instrumental e de modo a garantir a liberdade efetiva dos indivíduos e a "boa vida" tal como concebida dentro daquele local (LOADER; WALKER, 2006).

Os clientes portadores de drogas ilícitas não são vistos como uma ameaça à ordem do local, sendo, por isso, tratados com uma abordagem pouco atritiva. Essa visão e a postura dos seguranças constrastam fortemente, por exemplo, com aquelas que eles adotam em situações de violênica física (brigas) ou relacionadas a gênero (discriminações ou assédios) ocorridas no espaço analisado.

\begin{abstract}
Já teve casos que tivemos que tirar a pessoa a força porque ela estava agressiva lá dentro, já tinha agredido alguém e queria agredir de novo. Como nós não podemos deixar ninguém ser agredido dentro de nenhum estabelecimento, nós temos que pegar e por a pessoa que esta alterada pra fora até pra que não tenha mais problema ali dentro da casa (ENTREVISTA, 05/03/2020).

Ele se torna um cliente problemático quando vai lá no [nome da casa noturna] e tem alguma reclamação sua tipo 'ah, fulano veio aqui e passou a mão na bunda de não sei quem'. Com isso você é colocado pra fora na hora. Não tem tolerância pra assédio. [...] Assédio era uma coisa que na hora a gente bloqueava por tempo indeterminado, a pessoa ficava sem frequentar a casa (ENTREVISTA, 05/03/2020).
\end{abstract}

Depoimentos de alguns seguranças coletados na pesquisa de campo também mostraram que pessoas que brigam são o maior problema que a casa tem e não há nenhum tipo de tolerância com esse delito (CAMPO, 08/02/2020), assim como não há com as violências sexuais, como mostra a entrevista anterior. Nesse sentido, agressões físicas e sexuais são vistas como violações da ordem existente no espaço, exigindo ações contundentes da parte dos seguranças, tais como a expulsão da pessoa do local e a sua inclusão em uma lista que o impedirá de frequentar o local futuramente - o que os seguranças chamam de "bloquear" a pessoa. Embora não seja o propósito do trabalho 
analisar a maneira como os seguranças governam essas situações, vale notar que elas são processadas de maneira muito diferente das situações envolvendo pessoas portando ou consumindo drogas ilícitas. Enquanto, no primeiro caso, a pessoa é expulsa da casa e banida, no segundo, ela é apenas proibida de entrar ou de manter com a droga dentro do local.

Segundo a ex-segurança, o alcóol, que é uma droga lícita e cujo consumo é estimulado pelo estabelecimento, deve ser levado em consideração na triagem das pessoas que entram na casa, pois clientes barrados por se apresentarem "chapados" logo na entrada estão sujeitos a causar tumulto e a gerar desordem no local:

Se você já chegou alterado, você vai beber e você já está alterado. Você já está bebendo faz horas, estava lá em outra casa e vai parar no [nome da casa noturna] já alterado em torno das duas e meia, três horas da manhã. Opa, perai. Já vai entrar bêbado e chapado aqui? Aí já é problema... Um [cliente] já vai esbarrar nele, já vai brigar, já vai não sei o que, então é melhor prevenir do que remediar, a gente já bloqueava. Não deixava entrar. Bloqueava assim ó 'Você esta um pouco alterado, volta pra casa, amanhã você vem, você vai até se divertir mais' (ENTREVISTA, dia 05/03/2020).

Nessa lógica, é possível concluir que as drogas lícitas e ilícitas são governadas com uma mentalidade de gestão de riscos, que pode ser identificada na revista individual a qual os clientes são submetidos na entrada do estabelecimento. Esse tipo de policiamento que busca gerenciar os riscos fica evidente na fala da entrevistada, quando ela diz que "é melhor previnir do que remediar". Nota-se, aqui, uma mentalidade mais preocupada em tomar medidas capazes de prevenir comportamentos futuros indesejados do que em reprimir comportamentos desviantes já ocorridos (JOHNSTON, L; SHEARING, 2003).

Uma tecnologia que viabiliza a implementação dessa mentalidade é a lista de pessoas banidas do espaço. Estudos mostram que o banimento é um mecanismo de resolução de conflitos adotado pelas propriedades privadas de massa. Ele se baseia na capacidade de fato e de jure que os seguranças têm para excluir pessoas de espaços por meio de obstruções baseadas em comportamento passado; obstruções e expulsões baseadas em regras e comportamento presente; e obstruções baseadas em perfil social (HIRSCH \& SHEARING, 2000; LOPES, 2020). Nesse sentido, a lista de pessoas banidas do espaço é uma ferramenta para gerenciar quem pode ou não entrar na casa, minimizando os riscos de futuros comportamentos perturbadores da ordem, ou seja, a porta não é um mero local de entrada, mas é também onde ocorre a avaliação e a vigilância. Trata-se de uma tecnologia similar àquela que Hobbs e colegas descobriram em suas entrevistas com 
seguranças ingleses: "A porta é onde você começa. Para evitar problemas, você deve garantir que os clientes que entram sejam adequados (HOBBS et al. 2003, p. 121, tradução nossa) ${ }^{6}$.

Outra tecnologia que concretiza a mentalidade da gestão de risco é o modo como os seguranças gerenciam a ordem dentro da casa. O trecho a seguir, retirado do caderno de campo, revela isso:

\footnotetext{
Presenciei os seguranças em vários momentos dando sermão nos clientes. Senti que a função deles se assemelha com a de um árbitro, que vai apitando as regras do bar, reafirmando o que pode e não pode aos clientes que ficam no limite entre o permitido e o proibido (CAMPO, dia 19/10/2019).
}

Como o caderno de campo sugere, o diálogo é uma ferramenta fundamental para a equipe de segurança governar a ordem e implementar uma mentalidade de gestão de risco. Esse módus operandi foi confirmado na entrevista com a ex-segurança: "uma coisa que ele [gerente da casa] sempre deixou bem claro 'Aqui é na base da conversa, ninguém agride meus clientes"” (ENTREVISTA, dia 05/03/2020). É importante notar que os seguranças não têm o poder para dobrar vontades por meio da força, tal como a polícia estatal tem. Assim, mais uma vez, os dados acima demostram que o consenso instrumentalizado por meio do diálogo é fundamental para gerenciar os riscos e governar a ordem na casa noturna.

\section{CONSIDERAÇÕES FINAIS}

Este estudo pretendeu analisar de modo exploratório a governança de usuários de drogas em uma casa noturna de Londrina. Buscou-se saber como os usuários de drogas são tratados dentro desse espaço, de modo a contribuir para uma maior compreensão da maneira como os mercados de drogas são governados em nossa sociedade.

O trabalho revelou que os agentes de segurança privada agem em nome dos interesses da casa noturna pesquisada e, por isso, existe pouco atrito entre os seguranças e clientes usuários de drogas. O consenso é uma ferramenta indispensável para a implementação de uma mentalidade de gestão de riscos dentro da casa noturna. A postura pouco coercitiva dos seguranças com usuários de drogas reflete uma tentativa de manter a freguesia do local e evitar eventuais acusações de abuso de autoridade. Isso significa que os usuários de drogas, no contexto da casa noturna pesquisada, são

\footnotetext{
6 "The door is where you start. To prevent trouble, you have to make sure that the costumers coming in are suitable"
} 
governados de maneira mais instrumental e menos moral, ou seja, a casa noturna não está preocupada em combater as drogas, mas sim em investir esforços para a manutenção da freguesia, de modo que atenda melhor seus interesses.

\section{AGRADECIMENTOS}

Muitas pessoas contribuíram para a realização dessa pesquisa e quero agradecê-las. Inicialmente, agradeço à professora Leila Sollberger Jeolás pelas valiosas Oficinas Etnográficas ministradas ao Laboratório de Estudos sobre Governança da Segurança (LEGS). Agradeço enormemente aos integrantes do LEGS pelas leituras e considerações acerca deste trabalho. Um agradecimento especial ao meu orientador, professor Cleber da Silva Lopes, pela dedicação e pelos conhecimentos compartilhados ao longo desta IC. E por último, quero agradecer às pessoas entrevistadas, que cederam o seu tempo e a sua experiência para contribuir com esta pesquisa.

\section{REFERÊNCIAS}

BACHETT, H; LOPES, C. O Poder de Revista da Segurança Privada: os fundamentos e limites das revistas realizadas em consumidores. Revista Brasileira de Ciências Policiais. V. 11, p. 203-226, 2020;

BURRIS, Scott; DRAHOS, Peter; SHEARING, Clifford. Nodal governance. Australian Journal of Legal Philosophy. v. 30, p. 30-58, 2005;

FILHO, F. P. M. Administração institucional do uso de drogas. UFF/NUFEP, 2007;

HASSEM, M; KNAUTH, D; Victoria, C. Pesquisa Qualitativa em Saúde. Porto Alegre. Editora Tomo Editorial, 2000;

HIRSCH, A. VON; SHEARING, C. D. Exclusion from public space. In: HIRSCH, A. V.; GARLAND, D.; WAKEFIELD, A. (Eds.). Ethical and social perspectives on situational crime prevention. p. 241. Oxford (UK): Hart Publishing, 2000;

HOBBS, et al. Bouncers: Violence and Governance in the Nigth-time Economy. Oxford university press Inc., New York, 2003;

JOHNSTON, L.; SHEARING, C. Governing security: explorations in policing and justice. London: Routledge, 2003;

KEMPA, Michael; STENNING, Philip; WOOD, Jennifer. Policing communal spaces: a reconfiguration of the 'mass private property' hypothesis. British Journal of Criminology. v. 44, n. 4, p. 562-581, 2004; 
LEMGRUBER, J.; BOITEUX, L. "O Fracasso da Guerra às Drogas”. In LIMA, Renato Sérgio de; RATTON, José Luiz; AZEVEDO, Rodrigo Ghiringhelli (Orgs.). Crime, Polícia e Justiça no Brasil. Rio de Janeiro: Contexto, 2014, 640p;

LOADER, Ian; WALKER, Neil. Necessary virtues: the legitimate place of the state in the production of security. In: WOOD, Jennifer; DUPONT, Benoit (ed.). Democracy, society and the governance of security. Cambridge: Cambridge University Press, p. 165-195, 2006;

LOPES, Cleber da Silva. O setor de segurança privada da região metropolitana de São Paulo: crescimento, dimensões e características. Cad. CRH. Salvador, v. 26, n. 69, p. 599-617, dez. 2013;

(2015). Segurança privada e direitos civis na cidade de São Paulo. Soc. estado. Brasília, v. 30, n. 3 , p. $651-671$, dez. 2015 ;

(2018). As ferramentas legais universais da segurança privada: Um estudo sobre os direitos de questionar, usar força física e prender dos seguranças particulares brasileiros. Dilemas Revista de Estudos de Conflito e Controle Social. V. 11, n. 1, p. 97-126, Maio 2018;

(2020). Os poderes dos seguranças particulares no policiamento das propriedades privadas de massa. Revista Sociedade e Estado - Volume 35, Número 2, Maio/Agosto 2020;

MORAIS, P. C. C. Drogas e Políticas Públicas. Tese de Doutorado em Sociologia e Política. Universidade Federal de Minas Gerais: Belo Horizonte, 2006;

SANDERS, B. In the Club: Ecstasy Use and Supply in a London Nightclub. Sociology. 39 (2), p. 241-258, 2005;

SCHECAIRA, S. S. "Drogas e Criminologia". In LIMA, Renato Sérgio de; RATTON, José Luiz; AZEVEDO, Rodrigo Ghiringhelli de (Orgs.). Crime, Polícia e Justiça no Brasil. Rio de Janeiro: Contexto, 2014, 640p;

SHEARING, Clifford; STENNING, Philip. Private security: implications for social control. Social Problems. v. 30, n. 5, p. 493-506, 1983;

399-434, 1992;

(1992). The relation between public and private policing. Crime and Justice. v. 15, p. . (2006). Reflections on the refusal to acknowledge private governments. In: WOOD, Jennifer; DUPONT, Benoit (ed.). Democracy, society and the governance of security. Cambridge: Cambridge University Press, p. 11-32, 2006;

STENNING, P. C. Powers e accountability of private police. European Journal on Criminal Policy and Research. v. 8, n. 3, p. 325-352, Sep. 2000;

SØGAARD, T. F. HOUBORG, E. PEDERSEN, M. M. Drug policing assemblages: Repressive drug policies and the zonal banning of drug users in Denmark's club land. International Journal of Drug Policy. 41 (2017): 118-125; 
STRAUSS, Anselm; CORBIN, Juliet. Pesquisa Qualitativa: Técnicas e procedimentos para o desenvolvimento da teoria fundamentada. Tradução Luciane de Oliveira da Rocha. 2. Ed. Porto Alegre: Artmed, 2008.

WOOD, Jennifer; DUPONT, Benoit. Democracy, Society and the Governance of Security. Cambridge: Cambridge University Press (2006);

WOORTMANN, K. Sobre a formação de antropólogos. Anuário Antropológico. v. 21, n. 1, p. 0931, 6 fev. 2018. 